AperTO - Archivio Istituzionale Open Access dell'Università di Torino

\title{
Development of $\mathrm{O} / \mathrm{W}$ nanoemulsions for ophthalmic administration of timolol
}

\section{This is the author's manuscript}

Original Citation:

Availability:

This version is available http://hdl.handle.net/2318/125674

since 2016-07-14T12:51:58Z

Published version:

DOI:10.1016/j.jpharm.2012.10.015

Terms of use:

Open Access

Anyone can freely access the full text of works made available as "Open Access". Works made available under a Creative Commons license can be used according to the terms and conditions of said license. Use of all other works requires consent of the right holder (author or publisher) if not exempted from copyright protection by the applicable law. 


\section{(4) \\ UNIVERSITÀ DEGLI STUDI DI TORINO}

This Accepted Author Manuscript (AAM) is copyrighted and published by Elsevier. It is posted here by agreement between Elsevier and the University of Turin. Changes resulting from the publishing process - such as editing, corrections, structural formatting, and other quality control mechanisms - may not be reflected in this version of the text. The definitive version of the text was subsequently published in [DEVELOPMENT OF O/W NANOEMULSIONS FOR OPHTHALMIC ADMINISTRATION OF TIMOLOL, Volume 440, issue 2, 20 January 2013, http://www.sciencedirect.com/science/article/pii/S0378517312009556].

You may download, copy and otherwise use the AAM for non-commercial purposes provided that your license is limited by the following restrictions:

(1) You may use this AAM for non-commercial purposes only under the terms of the CC-BY-NC-ND license.

(2) The integrity of the work and identification of the author, copyright owner, and publisher must be preserved in any copy.

(3) You must attribute this AAM in the following format: Creative Commons BY-NC-ND license (http://creativecommons.org/licenses/by-nc-nd/4.0/deed.en), [+ Digital Object Identifier link to the published journal article on Elsevier's ScienceDirect ${ }^{\circledR}$ platform $]$ 


\title{
DEVELOPMENT OF O/W NANOEMULSIONS FOR OPHTHALMIC ADMINISTRATION
}

\section{OF TIMOLOL}

M. Gallarate, D. Chirio, R. Bussano, E. Peira, L. Battaglia, F. Baratta, M. Trotta

Dipartimento Scienza e Tecnologia del Farmaco, Università di Torino, via P. Giuria 9, 10125

Torino, Italy

Corresponding author: Marina Gallarate

mail: marina.gallarate@unito.it

via Pietro Giuria 9, 10125 Torino, Italy

Tel+39116707681 Fax +39116707687

\begin{abstract}
After an initial screening of ingredients and production methods, nanoemulsions for ocular administration of timolol containing the drug as maleate (TM) or as ion-pair with AOT (TM/AOT) were prepared. The physico-chemical characterisation of nanoemulsions, regarding mean diameter, $\mathrm{pH}$, Zeta potential, osmolarity, viscosity and surface tension, underlined their feasibility to be instilled into the eyes. Single components and emulsions were tested ex vivo on rabbit corneas to evaluate corneal irritation, that was measured according to opacity test. A marked decrease in corneal opacity was observed using the drug formulated in nanoemulsions rather than in aqueous solutions.
\end{abstract}


Drug permeation and accumulation studies were performed on excised rabbit corneas. An increase in drug permeation through and accumulation into the corneas were observed using TM-AOT compared to TM due to an increase of lipophilicity of the drug as ion-pair.

The introduction of chitosan (a positive charged mucoadhesive polymer) into emulsions allowed to increase TM permeation probably due to the interaction of chitosan with corneal epithelial cells.

Keywords: timolol, ion pair, nanoemulsions, ocular administration, corneal irritation 


\section{Introduction}

Ophthalmic application of drugs is the primary and patient well-accepted administration route for the treatment of various eye diseases.

Conventional liquid ophthalmic formulations demonstrate low bioavailability owing to a constant lacrimal drainage in the eye. Typically, ophthalmic bioavailabilities of only $1-10 \%$ are achieved due to the short precorneal residence time of solutions (Lee, 1993). Consequently, there is a need for frequent instillation of concentrated solutions to obtain the desired therapeutic effect. Moreover, systemic absorption of the drug drained through the nasolacrimal duct may result in some undesirable side effect.

To increase the effectiveness of the drug, the choice of the dosage form that should increase the contact time of the drug in the eye, increase the bioavailability and reduce systemic absorption is very important (Ammar et al, 2009). In literature, various ophthalmic vehicles such as suspensions, ointments, inserts and aqueous gels have been investigated to extend the ocular residence time of drugs for topical application to the eyes (Desai et al, 1994). These systems offer some improvement over conventional liquid vehicles, but they have not universally accepted owing to a few problems such as blurred vision and lack of patient compliance. Therefore good ocular bioavailability following topical delivery of a drug to the eye remains a challenge yet to be resolved satisfactorily (Felt et al, 1999).

TM is widely used as a topically applied $\beta$-adrenergic-blocking agent in ophthalmology to lower the intraocular pressure of glaucoma patients. It is well known that ocular administered TM may cause 
severe cardiovascular, respiratory and central nervous system side effects. To overcome these problems, various studies have been carried out: these included the use of stimuli-sensitive hydrogels (Gupta and Vyas, 2010), ocular inserts (Saettone and Salminen, 1995), ion pair (Higashiyama et al., 2004), microemulsions (Gallarate et al., 1988), niosomes (Aggarwal and Kaur, 2005).

Gupta et al (Gupta and Vyas, 2010) used polyacrylic acid as gelling agent in combination with chitosan as a viscosity-enhancing agent to formulate $\mathrm{pH}$-sensitive gel. This in situ gelling system was in liquid state at room temperature at $\mathrm{pH} 6.0$ and underwent rapid transition into the viscous gel phase at the $\mathrm{pH}$ of the tear fluid $(\mathrm{pH} 7.4)$. The in situ gelling system prepared with $0.4 \%$ Carbopol ${ }^{\circledR}$ and $0.5 \%$ chitosan prolonged the residence time of TM in the cul-de-sac and increased its bioavailability compared to a commercial TM solution. Moreover, this formulation decreased the drug systemic absorption.

Wadhwa et al. (Wadhwa et al., 2010) carried TM and dorzolamide hydrochloride in hyaluronic acid modified chitosan nanoparticles to promote a better interaction with ocular epithelium and to deliver the drug at ocular mucosal sites with longer residence time. Mucoadhesion strength study depicted that chitosan nanoparticles possess mucoadhesiveness which was increased by addition of hyaluronic acid. Transcorneal permeation studies showed a many fold increase in drug permeation from nanoparticles as compared to that of a marketed formulation.

In the last decade, $\mathrm{O} / \mathrm{W}$ emulsions have been investigated and are now exploited commercially as vehicles to improve the ocular bioavailability of lipophilic drugs (Tamilvanan and Benita, 2004). 
The natural biodegradability and substantial drug solubilization, either at the innermost oil phase or at the $\mathrm{O} / \mathrm{W}$ interphase and the improved ocular bioavailability are thus making lipid emulsions promising ocular delivery vehicles.

In this work TM was introduced in an $\mathrm{O} / \mathrm{W}$ nanoemulsion. Nanoemulsions are generally defined as oil-in-water emulsion droplets, with size ranging in the nanometric scale, typically $20-300 \mathrm{~nm}$; these appear to be transparent and translucent with a bluish color for the weak interaction with light and a high kinetic stability (Kabalnov et al., 1996). The droplets small size gives them inherent stability against creaming, sedimentation, flocculation, and coalescence (Fang et al., 2001). Nanoemulsions can be proposed as ocular eye drops in virtue of their distinct advantages, that include sustained release of the drug applied to the cornea, high penetration in the deeper layers of the ocular structure as well as ease of sterilization (Vandamme, 2002).

The main goal of the present work was to develop a nanoemulsion as ophthalmic dosage form, selecting the proper components in order to obtain a stable, non-irritating, isotonic formulation. An important aim was also to evaluate the amount of TM permeated from nanoemulsions through the excised cornea in ex vivo experiments. As the main corneal barrier to drug permeation is the lipophilic epithelium, transcorneal permeation of TM had to be enhanced by increasing TM lipophilicity; the contact time of the emulsion with the epithelium should also be enhanced by optimizing the emulsion external phase viscosity and its mucoadhesivity using different polymers. High molecular weight hydrophilic polymers usually employed as aqueous solutions thickeners owing to their hydrogen bonding capability, such as hydroxyethylcellulose, polyvinylalcohol and 
polyethylenglycol, were chosen. Chitosan was investigated as cationic polymer thanks to its possible interaction with the negative charges of the mucus. In vitro studies on different nanoemulsions were performed using albino rabbit corneas (Casterton et al., 1996): eye irritation potential was evaluated by a partially modified corneal opacity test. TM accumulation into and permeation through the cornea were also evaluated.

\section{Materials and methods}

\subsection{Materials}

Timolol maleate (TM), polivinylalcohol (PVA) 14000 and 85000, Pluronic ${ }^{\circledR}$ F68, low and medium viscosity chitosan (CS), benzalkonium chloride (BK), ethylenediaminetetraacetic acid (EDTA), N2-hydroxyethylpiperazine-N'-2-ethanesulfonic acid, taurine, N-acetyl-cisteine were from Sigma Chemical Co. (Milano, Italy). Polyethylenglycol (PEG) 100000 was from Dow (Milano, Italy). Hydroxyethylcellulose (Natrosol $\left.{ }^{\circledR} \mathrm{MR}\right)$, potassium sulfate, magnesium sulfate, calcium hydroxide, glycerol were from Acef (Piacenza, Italy). Isopropyl miristate (IPM), N-(tert-butyl) hydroxylamine $\mathrm{HCl}$, gentamycin sulfate, creatine phosphate were from Fluka (Buchs, Switzerland). Dextran MW 60,000-90,000 was from Serva (Heidelberg, Germany). Bis-(2-ethylexyl)-sulfosuccinate (AOT), Laspartic acid, potassium phosphate monobasic were from Merck (Darmstadt, Germany). Lipoid $^{\circledR}$ E80 (LP E80) was a grant of Natterman phospholipid GmbH (Köln, Germany); Tween ${ }^{\circledR} 80$ (TW80) was from Aldrich (St. Louis, MO, USA). Glutathione bicarbonate Ringer (GBR) was prepared according to literature (Camber, 1985); Steinhardt medium, a sterile medium for human 
corneas conservation, was prepared according to a patented formulation (Steinhardt, 2003). $\left[\mathrm{K}_{2} \mathrm{SO}_{4}\right.$ $5 \mathrm{mM}$, L-aspartic acid $(110 \mathrm{mM}), \mathrm{MgSO}_{4}(1.2 \mathrm{mM}), \mathrm{Ca}(\mathrm{OH})_{2}(2.0 \mathrm{mM}), \mathrm{KH}_{2} \mathrm{PO}_{4} 20 \mathrm{mM}, \mathrm{N}-2-$ hydroxyethylpiperazine-N'-2-ethanesulfonic acid $5 \mathrm{mM}$, ethylenediaminetetraacetic acid $1 \mathrm{mM}$, taurine $20 \mathrm{mM}, \mathrm{ZnSO}_{4} 1 \mu \mathrm{M}$, N-(tert-butyl) hydroxylamine HCL $(200 \mu \mathrm{M})$, dextran MW 60,000$90,0005.5 \% \mathrm{w} / \mathrm{v}, \mathrm{N}$-acetyl-cysteine $0.5 \mathrm{mM}$, gentamycin sulfate $0.02 \% \mathrm{w} / \mathrm{v}$, creatine phosphate 5 $\mathrm{mM}]$.

Distilled water was purified using a Milli-Q system (Millipore, Bedford, MO, USA). All other chemicals were analytical grade and used without further purification.

\subsubsection{Corneas}

New Zealand male albino rabbits were from slaughter house. The corneas were explanted from rabbit eye-balls, excised within 2 hours after animal death according to a protocol currently used for human corneas transplantation (Banca delle cornee della Regione Piemonte, 2006). A sclera ring of nearly $4 \mathrm{~mm}$ was maintained around the explanted corneas, which were kept at $4 \pm 1{ }^{\circ} \mathrm{C}$ in sterile Steinhardt medium less than 1 week.

Before corneal opacity test, corneas were assayed for their opacity by using the holder described below in the text, and corneas whose opacity exceeded 0.1 units of absorbance $(\lambda=570 \mathrm{~nm})$ were discarded (Casterton et al., 1996). 


\subsubsection{Corneal holders and diffusion chambers}

Corneal opacity test was performed on rabbit cornea by using a corneal holder as the one described in figure 1A. It consisted of a Plexiglas and glass structure, with a donor and a receiving compartment ( $0.65 \mathrm{ml}$ volume), respectively on the epithelial and on the endothelial side of the cornea, which has to be placed in the orifice $\left(\right.$ area $0.50 \mathrm{~cm}^{2}$ ) which divides the two compartments.

To minimize the irritation caused to the cornea by the holder itself, according to literature (Ubels et al., 2004), a Plexiglas cell was realized so that its o-ring clamped the scleral ring all around the cornea circumference; moreover, the holder structure allowed to maintain the natural cornea curvature. The holder was then housed in a spectrophotometer (Lambda 2 UV/VIS Perkin-Elmer) for opacity readings with the help of a suitable support, so that the beam crossed precisely the donor, the receptor compartment and the cornea clamped in the holder.

Accumulation and diffusion studies were performed by using a diffusion chamber (Figure 1B), analogous to the one described in literature (Camber, 1985).

\subsection{Ion pair preparation}

The TM/AOT ion pair was prepared by ion pairing method (Ogawa et al., 2002). Equal volumes of TM and AOT aqueous solutions at the same molar concentration were slowly mixed under magnetic stirring and stored at $5^{\circ} \mathrm{C}$ for further use. The final concentration was $1.00 \cdot 10^{-3} \mathrm{M}$ for both TM and AOT. 


\subsection{Evaluation of apparent partition coefficient}

The apparent partition coefficients $\left(\mathrm{P}_{\mathrm{app}}\right)$ of TM $\left(1.00 \cdot 10^{-3} \mathrm{M}\right)$ between water and 1-octanol or IPM in the absence and in the presence of AOT were investigated at $\mathrm{pH} 5.0$ or 7.2

$5 \mathrm{ml}$ aqueous solution of TM alone or in the presence of equimolar AOT (at $\mathrm{pH} 5.0$ or 7.2) were added to $5 \mathrm{ml} 1$-octanol or IPM in a separating funnel. The mixture was shaken for 5 minutes; after phase separating and resting for 12 hours, the aqueous solution was analyzed by high-performance liquid chromatography (HPLC) for TM determination. Each experiment was repeated thrice.

\subsection{HPLC analysis}

TM was determined by HPLC analysis using a system consisting of LC-10AD HPLC pump

(Shimadzu, Kyoto, Japan), UV-1575 variable wavelength ultraviolet detector (Jasko, GrossUmstadt, Germany) and a 4290 integrator (Varian, Santa Clara, USA). The quantitative determination of TM was performed by a reverse-phase HPLC chromatography on Alltech Allosphere ODS-2, $150 \mathrm{~mm}$ column. Chromatographic conditions were as follows: mobile phase: $\mathrm{H}_{2} \mathrm{O} / \mathrm{CH}_{3} \mathrm{OH} / \mathrm{N}\left(\mathrm{CH}_{3} \mathrm{CH}_{2}\right)_{3}(30: 70: 0.1 \mathrm{~V} / \mathrm{V})$, brought to $\mathrm{pH} 3.5$ with $\mathrm{CH}_{3} \mathrm{COOH}$; injected volume: $20 \mu \mathrm{l}$; flux: $1 \mathrm{ml} / \mathrm{min} ; \lambda: 294 \mathrm{~nm}$; RT: $3.9 \mathrm{~min}$.

A calibration graph was constructed in the $1.0 \cdot 10^{-5}-5.0 \cdot 10^{-4} \mathrm{M}$ range (seven points, each determined in quadruplicate). The linearity of the calibration graph was demonstrated by the value (0.9932) of $R^{2}$ coefficient of the regression equation: $y=8 E+09 x+174567$. The limit of quantification (LOQ), defined in the presented experiment as the lowest timolol concentration in the curve that can be 
measured routinely with acceptable precision and accuracy, was $1 \cdot 10^{-5} \mathrm{M}$; the limit of determination (LOD), defined as the lowest detection limit, was $3.5 \cdot 10^{-6} \mathrm{M}$ (signal to noise 2.0).

\subsection{Emulsion preparation}

After an initial screening of several potential emulsion components (IPM, Dermol ${ }^{\circledR}$ M5 /(capryccaprylic triglyceride) soya oil as lipidic phase; LP E80, Epikuron ${ }^{\circledR} 200$ (soya lecithin), Phospholipon ${ }^{\circledR} 90 \mathrm{H}$ (hydrogenated soya lecithin), TW80 and Pluronic ${ }^{\circledR}$ F68 as emulsifying agents), IPM was selected as lipophilic disperse phase, TW80 and LP E80 as emulsifying agents and $\mathrm{BK}$ as antimicrobial agent. The resulting formulations are reported in Table 1. The base formulation (EM1) had the following composition: 5\% IPM, 1\% LP80, 1.5\% TW80, 0.1\% EDTA, $0.02 \%$ BK, $2.5 \%$ glycerol, water q.b. $100 \%$.

Briefly, emulsions were prepared as follows: LP E80 it was first dissolved in IPM and then other components were added. The mixture was mixed for 10 minutes at $15000 \mathrm{rpm}$ with rotational homogenizer (IKA ${ }^{\circledR}$ T25 Ultra-TURRAX ${ }^{\circledR}$, Germany). After adjusting pH of the pre-emulsion to a value of 7.2 with $1 \mathrm{M} \mathrm{NaOH}$, it was subjected to high pressure homogenization (Panda, Niro Soavi, Italy) for 3 cycles of 5 minutes at 1000 bar.

Viscous emulsions were prepared as just described using different polymer (low and medium viscosity CS, HEC, PVA 14000 and 85000, PEG 100000) solutions as aqueous phase of the emulsion 
HEC, PVA 14000 and 85000, PEG 100000 solutions were prepared in hot water under magnetic stirring.

Low and medium viscosity CS solutions were prepared by dissolving an appropriate amount of polymer in hot $1 \mathrm{M} \mathrm{HCl}$ under magnetic stirring; CS solutions were then dialyzed using Visking ${ }^{\circledR}$ membranes to remove the $\mathrm{HCl}$ in excess.

Drug-containing emulsions were prepared as described above using TM or TM/AOT ion pair as aqueous phase. Each emulsion batch was prepared in triplicate.

\subsection{Sterile filtration}

To obtain sterile formulations, the undiluted emulsions were filtered through Millipore Millex ${ }^{\circledR}$ GS MF $0.22 \mu \mathrm{m}$ (Bedford, MA) assembled to the bottom of a sterile syringe under sterile conditions. The filtrate was collected, diluted with distilled water and analyzed with photon correlation spectroscopy technique. The difference of kcps before and after filtration indicated the filtration feasibility, while the differences of particle size and polydispersity index were used as indicators of physical stability.

\subsection{Emulsion characterization}

Drop mean diameter and polydispersity index were determined in triplicate by photon correlation

spectroscopy (90 Plus, Brookhaven Instrument, Holtsville, NY, USA). Measurements were performed at $25^{\circ} \mathrm{C}$ at an angle of $90^{\circ}$. All samples were obtained by diluting emulsions with filtered 
water. Scattering intensity data were analyzed by a digital correlator and fitted by the method of inverse Laplace transformation.

Zeta potential measurements were performed using 90 Plus zetasizer (Brookhaven Instrument Holtsville, NY, USA). Measurements were performed on water diluted emulsions adjusting the conductivity to $300 \mu \mathrm{S} / \mathrm{cm}$ by $\mathrm{KCl}$ addition.

Emulsion viscosities were determined by capillary viscometer (Shott-Geräte Gmbh, Germany) equipped with $k=0.02997$ capillary suitable for measuring viscosity in the range between 1.2 and 18 $\mathrm{mPa} \cdot \mathrm{s}$. Measurements were conducted at $25 \pm 0.1{ }^{\circ} \mathrm{C}$ and repeated four times.

Surface tension of each emulsion was determined using a Krüss Interfacial Tensiometer K10 PST (Krüss, Germany) equipped with a platinum ring. Measurements were carried out in triplicate on 20 $\mathrm{ml}$ of each emulsion introduced into a thermostatically controlled glass at $25 \pm 0.1^{\circ} \mathrm{C}$.

To determine emulsions osmolarity, a Semi-Micro Osmometer K-7400 (Knauer, Berlin, Germany) was used: $150 \mu \mathrm{l}$ of each emulsion were introduced in the glass capillary and then into the instrument. Measurements were carried out in triplicate.

\subsection{Stability studies}

To verify samples physical stability, emulsions were subjected to centrifugation at $766 \mathrm{~g}$ at $25{ }^{\circ} \mathrm{C}$ for 4 cycles of 5 minutes (Allegra 64R, Beckman Coulter, USA). 
Moreover, two aliquots of the prepared emulsions were stored for 3 months at $25.0{ }^{\circ} \mathrm{C}$ and at $40.0^{\circ} \mathrm{C}$ in sealed eye drop bottles for accelerated stability studies. At predetermined intervals the preparations were subjected to dimensional analysis (LLS) and $\mathrm{pH}$ measurements.

\subsection{Adhesion test}

To study the influence of CS on corneal adhesion, an in vitro method was developed.

A gel with the same surface tension of tear fluid $(28$ dyne $/ \mathrm{cm})$ was prepared; the gel had the following composition: 5\% HEC, 1\% decylpolyglucoside, 3\% hyaluronic acid, water q.b. 100\%.

The gel was spread on a 50x10 cm glass support and kept to rest until hardening was reached.

$25 \mu 1$ of each sample were placed onto the shorter side of the hardened gel and the support was sloped of $18^{\circ}$. The time needed to flow over a distance of $25 \mathrm{~cm}$ was evaluated for each preparation.

The flow rate was calculated as distance/time $(\mathrm{cm} / \mathrm{s})$.

Samples under study: water, EM1, EM2, EM3, EM4, EM5, EM7.

\subsection{Corneal opacity}

Corneal opacity test was performed on albino rabbit cornea adapting the method BPCO widely used for the evaluation of corneal toxicity (Casterton et al., 1996).

The opacity test was performed by clamping the cornea, through its scleral ring, in the appropriate holder, and filling both the compartments with GBR buffer. Then, in the donor compartment, GBR buffer was substituted by a solution of the irritation standards or by the formulations under study for 
1 or 10 minutes. Samples were then withdrawn, the donor compartment was washed three times with GBR buffer and equilibrated with the same buffer for at least 15 minutes. Opacity was measured by determining the absorbance of the cornea $(\lambda=570 \mathrm{~nm})$ clamped in the holder, before and after incubation with standards or formulations.

Samples under study: solutions of single emulsion components $(0.015 \%$ BAK, $2.0 \%$ PVA 14000 , 1.0\% PVA $85000,0.5 \%$ low-viscosity CS, $0.8 \%$ medium-viscosity CS, $1.0 \%$ PEG $100000,0.2 \%$ HEC) and of irritation standards $(1 \mathrm{M} \mathrm{NaOH}, 1.5 \%$ TW80), blank (EM1, EM2, EM3, EM4, EM5, EM6, EM7) and drug-loaded (EM8, EM9, EM10, EM11) emulsions. GBR buffer was used as control.

\subsection{Accumulation and diffusion studies}

Accumulation and diffusion studies were performed by using a diffusion chamber analogous to the one described in literature (Camber, 1985).

Corneas were mounted between the two halves of the diffusion cell: the diffusion available area was

$0.63 \mathrm{~cm}^{2}$, the donor compartment $(0.8 \mathrm{ml})$ was filled with $\mathrm{TM}$ and TM/AOT-loaded formulations, while the receptor compartment ( $3 \mathrm{ml})$ was filled with GBR buffer. The diffusion chamber was kept at $35 \pm 1{ }^{\circ} \mathrm{C}$. After 1,2 and 3 hours, drug permeated through the excised cornea was determined by HPLC analysis of the receiving phase. The integrity of the epithelium after the experiment was checked by optical microscopy observation. No oxygenation of the perfusion apparatus seemed to 
be needed, according to the short experiment time, as described in some literature reports (Ahuja, 2006, Han et al., 2010). Drug accumulation was evaluated by HPLC analysis: after 3 hours the drug was extracted from corneas with $\mathrm{H}_{2} \mathrm{O} / \mathrm{CH}_{3} \mathrm{OH} / \mathrm{N}\left(\mathrm{CH}_{3} \mathrm{CH}_{2}\right)_{3}$ 70/30/0.1 (V:V) overnight, after careful removal of the corneas from diffusion cells and washing with tap water (Hung-Hong et al., 1996). Each determination was carried out on six corneas.

Samples under study: TM and TM/AOT solutions at pH 5.0 and 7.2, emulsions EM8, EM9, EM10 (only accumulation study), EM11.

\subsection{Statistical analysis}

The statistical comparison was performed by a Student t-test with $\mathrm{p}$-value $<0.05$ as the significant value.

\section{Results and discussion}

\subsection{Emulsion preparation and characterization}

The first phase of this research was aimed to formulate an $\mathrm{O} / \mathrm{W}$ nanoemulsion and to evaluate the influence of the ingredients on physico-chemical characteristics and on the stability of the emulsion to be proposed for ophthalmic application.

Preliminary screening on several lipids (IPM, soya oil, Dermol®M5) phospholipids (LP E80, Epikuron ${ }^{\circledR} 200$, Phospholipon $\left.{ }^{\circledR} 90 \mathrm{H}\right)$ and surfactants $\left(T W ® 80\right.$ and Pluronic ${ }^{\circledR}$ F68) was carried out to optimize emulsion composition regarding its physical stability. The results of this formulative 
section evidenced IPM as the most suitable lipid to be used as disperse phase; this lipid, present in the European Pharmacopoeia, is commonly employed as an excipient in topical formulations (Badmapriya and Rajalakshmi, 2010) and it is also adopted as a drug penetration promoter in transdermal or topical formulations (Suh and Jun, 1996). 5\% w/w disperse phase was used, a value normally used in ophthalmic emulsions, to avoid blurred vision (Tamilvanan and Benita, 2004).

LP E80, a mixture of phospholipids derived from egg yolk and TW 80, a nonionic surfactant and emulsifier widely used in ocular preparations classified as practically non-irritating (Hussein et al., 2009) were used as emulsifiers.

To increase emulsion viscosity, the following polymers were selected and used at different concentrations: low viscosity CS, medium viscosity CS, medium viscosity HEC (Ludwig, 2005), PVA 14000, PVA 85000 (Thermes et al., 1992), PEG 100000. Moreover, the important role played by CS in mucoadhesion has been described in literature (Gordon et al., 2010)

Emulsion compositions are reported in Table 1. As the aim was to perform a preliminary study on the possibility of TM TM/AOT to be loaded in nanoemulsions, and to evaluate the influence of chitosan on drug corneal diffusion and accumulation, independently of its viscosity, only the base composition emulsion and that containing low-viscosity CS were prepared in the presence of the drug. TM concentration in each emulsion was always $1.00 \cdot 10^{-3} \mathrm{M}$. Formulations were characterized determining mean diameter of oil droplets, $\mathrm{pH}$, Zeta $(\zeta)$ potential, osmolarity, viscosity $(\eta)$ and superficial tension $(\gamma)$. Results are summarized in Table 2. Mean diameters, surface tension and osmolarity values were quite similar in all emulsions prepared. All emulsions 
showed an initial $\mathrm{pH}$ of about 2.8. Emulsions without $\mathrm{CS}$ were adjusted to the physiological $\mathrm{pH}$ value 7.2, except than for CS-containing emulsions (EM2, EM3, EM9, EM10) that were brought to pH 5.00 to avoid CS precipitation at higher $\mathrm{pH}$ values.

The presence of the different polymers determined only a slight increase in mean diameters, which remained below $100 \mathrm{~nm}$, allowing the maintainance of a nanostructured system. The viscosity of EM1 was $1.58 \mathrm{mPa}$ s and increased up to 2.5 times depending on polymer type and concentration, except than in the presence of CS, which seemed not to influence emulsion viscosity. Because the adequate viscosity for ophthalmic preparation is considered to be from 2 to $3 \mathrm{mPa}$ (Tamilvanan and Benita, 2004), all lipid emulsions prepared with different polymers can be considered appropriate to be instilled into the eyes.

Surface tension of emulsions was in the $31.3-31.9 \mathrm{mN} / \mathrm{m}$ range, slightly lower than the tear fluid. This result was expected because the surfactants used in their preparation lower the oil-water surface tension. Although tear film is destabilized when surface tension of ophthalmic dosage forms is much lower than its surface tension, which is between 40 and $50 \mathrm{mN} / \mathrm{m}$ (Ciba-Geigy, 1977, Tiffany, 2006), lower surface tension values in emulsions generally ensure a good spreading effect on the cornea and mixing with the film constituents, increasing the contact between the drug and the corneal epithelium (Hasse and Keipert, 1997, Ligório and daSilva-Cunha, 2004).

Emulsions without CS had a negative Zeta potential mainly due to the charge of phospholipids present at the interface. On the other hand, in emulsions EM2, EM3, EM10 and EM11, CS determined a positive charge on the droplet surface and consequently positive Zeta potential. CS 
positively-charged amine groups could interact with the negatively charged mucous layer conferring a mucoadhesive characteristic and prolonging contact time with the ocular surface (Felt et al., 1999, Wei, et al., 2011). In vitro evaluation of polymer bioadhesion, expressed as the force required to separate a polymer specimen from a freshly excised rabbit conjunctival membrane can be measured by using a precision balance. (Indu and Meenakshi, 2002) In the present work, an alternative in vitro method not involving animal sacrifice was adopted.

In Figure 2 results of adhesion test are reported. The aqueous solution presented the highest flow rate on the gel surface, probably predicting a rapid in vivo distribution on corneal epithelium due to its low viscosity and a consequent fast drainage and elimination. All emulsions tested presented lower flow rates than the aqueous solution owing to the presence of a disperse structure. When a polymer was added, only a certain decrease in flow rate was noted, probably due to a slight increase in viscosity; the up to 3-fold decrease in flow rate obtained in the presence of chitosan (EM3) seems to be mainly due to its adhesive properties rather than to an increase of the viscosity (as reported in Table 2). The decrease of flow rate might imply an increase of the contact time with corneal epithelium.

Osmolarity of tear fluid is between 280 and 293 mOsm; solutions with osmolarity lower than 100 mOsm or higher than 640 mOsm are considered irritants (Van Ooteghem, 1993). Hence all emulsions have osmolarity values well-tolerated by the eye. 
To evaluate the physical stability of the different systems, emulsions were subjected to 4 cyclecentrifugation at $766 \mathrm{~g}$ for of 5 minutes each: no sample showed signs of phase separation; similar results, obtained also in the presence of TM and TM/AOT, indicated that drug loading did not cause system destabilization.

Over time-stability studies were carried out 3 months measuring mean diameters and polydispersity index of different emulsions stored at $25.0{ }^{\circ} \mathrm{C}$ and at $40.0{ }^{\circ} \mathrm{C}$ in sealed glass eye-drop bottles. As reported in Figures $3 \mathrm{~A}$ and $3 \mathrm{~B}$, at $25^{\circ} \mathrm{C}$ all samples subjected to dimensional analysis did not exhibit significant increases in droplet sizes, except than EM5, EM6 and EM7 containing PVA 14000, PVA 85000 and PEG 100000 respectively, which showed the greatest size increase. Such trend was partially confirmed at $40{ }^{\circ} \mathrm{C}$ : after 6 month-storage EM5 and EM6 showed mean diameter increase up to $140 \mathrm{~nm}$. In all other cases, at both storage temperatures, mean sizes still remained lower than $100 \mathrm{~nm}$, so that the systems under study were considered as stable nanoemulsions.

Emulsions were also subjected to $\mathrm{pH}$ measurements at the same times to assess possible changes over time. As observed in Table 3, in all emulsions a slight decrease in $\mathrm{pH}$ value was observed, but within the accepted range of $\mathrm{pH}$ for ophthalmic administration. It is assumed that the $\mathrm{pH}$ decrease is due to the formation of free fatty acids from lecithin (Herman and Groves, 1992). The main degradation process is related to the hydrolysis of the diacyl phosphatidylcholines and diacyl phosphatidylethanolamines to their corresponding monoacyl (lyso) derivatives and free fatty acid moieties. In turn, the lyso derivatives can degrade to their corresponding glycerophosphoryl 
compounds, with the formation of additional fatty acids. The emulsion systems are unbuffered and the formation of fatty acids will inevitably lower the $\mathrm{pH}$ from the initial value.

The basic requirement for ophthalmic formulations is sterility (Furrer et al., 2002); as a preliminary test, conducted by heating the emulsions in autoclave at $121^{\circ} \mathrm{C}$ for 15 minutes, led to complete phase separation, emulsions were submitted to sterile filtration using a $0.22 \mu \mathrm{m}$ Millipore filter.

After sterilization, all emulsions underwent only slight reductions (max 15\%) in mean diameters as reported in Table 4. Therefore emulsions can be subjected to sterilization by filtration.

\subsection{Corneal opacity}

Bovine corneal opacity and permeability (BCOP) test is an in vitro irritation test proposed in literature (Casterton et al, 1996; Gautheron et al., 1992): it measures the irritation caused by substances and formulations after exposure to bovine corneas, by evaluating the increase in corneal opacity and in corneal permeability. The evaluation of common standard irritants provides an empirical irritation scale. The bovine cornea opacity and permeability assay, from which our method was adapted, measures two important components of ocular irritation affecting the cornea, opacity and permeability. Irritant-induced opacity, which is experimentally determined by the amount of light transmission through the cornea, is an indicator of protein denaturation, swelling, vacuolization or damage in the epithelial and/or stromal layers. 
In the present study, only corneal opacity test was performed and rabbit corneas were used, owing to the easy of handling, inexpensiveness and availability of rabbit eyes. Moreover, they are generally more susceptible to irritating substances that the eyes of humans (Wilhelmus, 2001).

Each formulation was compared with a standard of irritation $(1 \mathrm{M} \mathrm{NaOH})$ and with GBR buffer.

In Figure 4 the variations of cornea absorbance after exposure are reported. It can be observed that while GBR buffer, as expected, had no irritation power, $1 \mathrm{M} \mathrm{NaOH}$ induced a considerable increase (0.8) in absorbance after $10 \mathrm{~min}$ exposure and thus serious opacity of the cornea (Casterton et al, 1996). Aqueous solutions of BK, TW 80 and various polymers at the same concentration used in the emulsions induce only a slight increase in opacity ( $\Delta$ abs always lower than 0.3 ) and this effect seems to be attenuated in the emulsive systems ( $\Delta$ abs always lower than 0.1 ), which played a protective role.

In Figure 5 the variations of cornea absorbance after exposure of TM and TM/AOT containing aqueous solutions and nanoemulsions are reported. After 1 minute exposition, almost no irritation effect was noted among all systems under study; indeed, neither drug-carrying emulsions, nor TM aqueous solutions determined significant increase in corneal opacity when compared with GBR solution ( $\Delta$ abs always lower than 0.05$)$. After 10 minutes, all emulsion systems produced only a slight increase in $\Delta \mathrm{abs}$, which remained lower than 0.05 , other than TM and TM/AOT aqueous solutions ( $\Delta$ abs up to 0.2 ). This results could confirm a certain protective effect of nanoemulsions against corneal irritation 


\subsection{Accumulation and diffusion studies}

TM accumulation and corneal diffusion studies were carried out after 1 and 3 hours application.

EM8 and EM9 (without CS) and EM10 and EM11 (with CS) containing both TM and TM/AOT respectively, were analyzed (Figure 4) and compared with TM and TM/AOT aqueous solution at the same concentration and $\mathrm{pH}$. The attention was focused on CS-containing emulsions to evaluate if the mucoadhesive properties of CS itself can influence TM permeation and accumulation, excluding an eventual viscosity influence, as no increase in viscosity was noted in the presence of CS, differently from other polymer used (Table 2).

The amounts of TM diffused through the cornea over time are reported in Fig. 6.

As can be observed, both in aqueous solutions and in nanoemulsions, the diffusion rate of TM through the cornea increased in the presence of AOT as counterion, indicating a higher permeation of the lipophilic ion pair. This trend can be observed at both the $\mathrm{pH}$ values considered (5.0 and 7.2) but it was more evident in solutions than in emulsions where the drug is mainly partitioned in the inner phase. Indeed, at pH 5.0 TM flux, calculated from the slope of the curve (Figure 6) obtained reporting TM amount diffused vs time (in the 1-3 hours range) increased from $714 \mathrm{ng} / \mathrm{cm}^{2} / \mathrm{h}$ up to $7752 \mathrm{ng} / \mathrm{cm}^{2} / \mathrm{h}$ in the presence of the counterion. A similar trend, even if in a smaller extent, (from 1015 to $7224 \mathrm{ng} / \mathrm{cm}^{2} / \mathrm{h}$ ) was observed at $\mathrm{pH} \mathrm{7.2,} \mathrm{confirming} \mathrm{the} \mathrm{role} \mathrm{of} \mathrm{the} \mathrm{lipophilic} \mathrm{ion} \mathrm{pair} \mathrm{in}$ corneal permeation. 
In Table 5 TM apparent partition coefficients $\mathrm{P}_{\text {app }}$ (IPM/water and octanol/water) are reported. The increase of octanol/water $\mathrm{P}_{\text {app }}$ of TM/AOT ion pair respect TM was almost 40 times at $\mathrm{pH} 7.2$ and 80 times at $\mathrm{pH} 5.0$ and underlined the actual lipophilization of the drug.

Comparing EM8 (containing TM) with EM9 (containing TM/AOT), both at pH 7.2, only a slight increase in the flux (from 1332 to $2025 \mathrm{ng} / \mathrm{cm}^{2} / \mathrm{h}$ ) was noted, indicating that the lipophilicity enhancement of the ion pair is counterbalanced by its pronounced partition in the disperse phase of the nanoemulsion (Table 5).

In addition, the introduction of CS counter in the emulsion containing TM/AOT at pH 5.0 (EM11) produced the highest diffusion rate (flux $12155 \mathrm{ng} / \mathrm{cm}^{2} / \mathrm{h}$ ) (Figure 6). This effect is probably due to positive charges $(+16.45 \mathrm{mV}$ Zeta potential) conferred by CS to the droplets, which allows interactions with the negative charges of mucin and consequently a stronger bioadhesion on the precorneal area (De la Fuente et al., 2010, Wei, J. et al., 2011).

Analyzing 3-hour drug accumulation in the corneal tissue, it can be observed (Figure 7) how the presence of ion pair facilitates the drug accumulation from aqueous solutions, with a statistically significant difference, probably due to the higher ion pair lipophilicity and consequently to its higher affinity for the lipophilic epithelium of the cornea.On the contrary, at both $\mathrm{pH}$ values, the presence of TM/AOT in emulsive systems seems not to positively influence TM/AOT ion pair accumulation when compared with the corresponding aqueous solutions, probably as a consequence of ion pair partition in the lipophilic disperse phase. 


\section{Conclusions}

This work focused the possibility of using oil-in-water nanoemulsions as a drug delivery system to the eye.

Initial screening on the safety of components and on production methods led to a range of stable, biocompatible, sterilizable and non-irritating nanoemulsions. The formulations were stable over time at $25{ }^{\circ} \mathrm{C}$ and $40{ }^{\circ} \mathrm{C}$ and showed properties such as $\mathrm{pH}, \zeta$ potential, osmolarity, viscosity and surface tension suitable for ocular administration.

The use of thickening and/or mucoadhesive polymers (CS, HEC, PVA, PEG) significantly increases the viscosity of the preparation which could therefore presumably achieve in vivo a prolonged residence time on the preocular surface.

Hydrophobic ion pairing of timolol with AOT led to a significant increase of corneal permeation of the drug both in solutions and in emulsions.

Furthermore, the presence of chitosan in nanoemulsions led to a marked increase in drug permeation, probably due to interactions with the negative charges present on the eye surface.

In conclusion, the biodegradability and ocular tolerability of the components, the droplet sizes in the nanometer range, the possibility of sterilization and a good long term stability of the developed formulations make the lipid nanoemulsion a promising drug delivery system for ophthalmic application. 


\begin{tabular}{|c|c|c|c|c|c|c|c|c|c|c|}
\hline \multirow{2}{*}{ COMPONENTS } & \multicolumn{10}{|c|}{ EMULSIONS } \\
\hline & $\begin{array}{c}\text { EM } \\
2\end{array}$ & $\begin{array}{c}\text { EM } \\
3\end{array}$ & $\begin{array}{c}\text { EM } \\
4\end{array}$ & $\begin{array}{c}\text { EM } \\
5\end{array}$ & $\begin{array}{c}\text { EM } \\
6\end{array}$ & $\begin{array}{c}\text { EM } \\
7\end{array}$ & EM 8 & EM 9 & EM 10 & EM 11 \\
\hline low visc $\mathrm{CS}$ & 0.5 & & & & & & & & 0.5 & 0.5 \\
\hline med visc $\mathrm{CS}$ & & 0.8 & & & & & & & & \\
\hline HEC & & & 0.2 & & & & & & & \\
\hline PVA 14000 & & & & 2 & & & & & & \\
\hline PVA 85000 & & & & & 1 & & & & & \\
\hline PEG 100000 & & & & & & 1 & & & & \\
\hline $\mathrm{TM}$ & & & & & & & $\begin{array}{c}1.0 \cdot 10^{-3} \\
\mathrm{M} \\
(0.043)\end{array}$ & $\begin{array}{c}1.0 \cdot 10^{-3} \\
\mathrm{M} \\
(0.043)\end{array}$ & $\begin{array}{c}1.0 \cdot 10^{-3} \\
\mathrm{M} \\
(0.043)\end{array}$ & $\begin{array}{c}1.0 \cdot 10^{-3} \\
\mathrm{M} \\
(0.043)\end{array}$ \\
\hline AOT & & & & & & & & $\begin{array}{c}1.00 \cdot 10^{-3} \\
\mathrm{M} \\
(0.043)\end{array}$ & & $\begin{array}{c}1.00 \cdot 10^{-3} \\
\mathrm{M} \\
(0.043)\end{array}$ \\
\hline
\end{tabular}

Tab. 1 


\begin{tabular}{|c|c|c|c|c|c|c|}
\hline $\mathbf{E M . ~}$ & $\begin{array}{c}\text { Mean } \\
\text { diameters } \\
(\mathrm{nm})\end{array}$ & $\mathbf{p H}$ & $\begin{array}{c}\boldsymbol{\zeta} \\
(\mathrm{mV})\end{array}$ & $\begin{array}{c}\text { osmolarity } \\
(\mathrm{osm})\end{array}$ & $\begin{array}{c}\boldsymbol{\eta} \\
(\mathrm{mPa} \cdot \mathrm{s})\end{array}$ & $\begin{array}{c}\boldsymbol{\gamma} \\
(\mathrm{mN} / \mathrm{m})\end{array}$ \\
\hline $\mathbf{1}$ & $58.0 \pm 1.9$ & $7.2 \pm 0.2$ & $-25.85 \pm$ & $0.384 \pm 0.034$ & $1.58 \pm 0.01$ & $31.3 \pm 3.2$ \\
\hline $\mathbf{2}$ & $71.9 \pm 0.6$ & $5.0 \pm 0.1$ & $16.30 \pm$ & $0.332 \pm 0.032$ & $1.63 \pm 0.02$ & $31.8 \pm 2.5$ \\
\hline $\mathbf{3}$ & $71.0 \pm 0.8$ & $5.1 \pm 0.1$ & $34.90 \pm$ & $0.349 \pm 0.040$ & $1.87 \pm 0.02$ & $31.9 \pm 3.0$ \\
\hline $\mathbf{4}$ & $62.3 \pm 0.9$ & $7.2 \pm 0.2$ & $-23.34 \pm$ & $0.321 \pm 0.027$ & $2.04 \pm 0.03$ & $31.7 \pm 3.4$ \\
\hline $\mathbf{5}$ & $65.1 \pm 0.1$ & $7.2 \pm 0.2$ & $-33.15 \pm$ & $0.362 \pm 0.031$ & $3.27 \pm 0.03$ & $31.8 \pm 3.4$ \\
\hline $\mathbf{6}$ & $68.6 \pm 0.1$ & $7.3 \pm 0.2$ & $-35.41 \pm$ & $0.364 \pm 0.041$ & $2.44 \pm 0.02$ & $31.6 \pm 3.2$ \\
\hline $\mathbf{7}$ & $68.4 \pm 0.5$ & $7.2 \pm 0.2$ & $-26.55 \pm$ & $0.351 \pm 0.039$ & $2.21 \pm 0.02$ & $31.7 \pm 3.0$ \\
\hline $\mathbf{8}$ & $60.2 \pm 1.6$ & $7.2 \pm 0.2$ & $-24.60 \pm$ & $0.386 \pm 0.040$ & $1.60 \pm 0.01$ & $31.3 \pm 3.7$ \\
\hline $\mathbf{9}$ & $56.3 \pm 1.5$ & $7.2 \pm 0.2$ & $-26.89 \pm$ & $0.379 \pm 0.050$ & $1.50 \pm 0.01$ & $31.4 \pm 3.4$ \\
\hline $\mathbf{1 0}$ & $73.5 \pm 1.1$ & $5.0 \pm 0.1$ & $18.25 \pm$ & $0.345 \pm 0.027$ & $1.70 \pm 0.01$ & $31.8 \pm 3.5$ \\
\hline $\mathbf{1 1}$ & $74.5 \pm 0.9$ & $5.0 \pm 0.1$ & $16.45 \pm$ & $0.355 \pm 0.034$ & $1.60 \pm 0.01$ & $31.6 \pm 3.2$ \\
\hline
\end{tabular}

Tab. 2

\begin{tabular}{|c|c|c|c|c|c|c|c|c|c|}
\hline EM. & $\mathrm{T}$ & $\mathrm{t}_{0}$ & $24 \mathrm{~h}$ & 1 week & 2 weeks & 3 weeks & 1 month & $\begin{array}{c}2 \\
\text { months }\end{array}$ & 3 months \\
\hline \multirow{2}{*}{1} & $25^{\circ} \mathrm{C}$ & \multirow{2}{*}{$\begin{array}{c}7.2 \pm \\
0.2\end{array}$} & $\begin{array}{c}7.1 \pm \\
0.2\end{array}$ & $\begin{array}{c}6.9 \pm \\
0.2\end{array}$ & $\begin{array}{c}6.8 \pm \\
0.2\end{array}$ & $6.7 \pm 0.2$ & $6.6 \pm 0.2$ & $\begin{array}{c}6.4 \pm \\
0.2\end{array}$ & $6.4 \pm 0.2$ \\
\hline & $40^{\circ} \mathrm{C}$ & & $\begin{array}{c}6.9 \pm \\
0.2 \\
\end{array}$ & $\begin{array}{c}6.7 \pm \\
0.2 \\
\end{array}$ & $\begin{array}{c}6.6 \pm \\
0.2 \\
\end{array}$ & $6.6 \pm 0.2$ & $6.5 \pm 0.2$ & $\begin{array}{c}6.4 \pm \\
0.2 \\
\end{array}$ & $6.3 \pm 0.2$ \\
\hline \multirow{2}{*}{2} & $25^{\circ} \mathrm{C}$ & \multirow{2}{*}{$\begin{array}{c}5.0 \pm \\
0.1\end{array}$} & $\begin{array}{c}4.9 \pm \\
0.1\end{array}$ & $\begin{array}{c}4.8 \pm \\
0.1\end{array}$ & $\begin{array}{c}4.8 \pm \\
0.1 \\
\end{array}$ & $4.7 \pm 0.1$ & $5.0 \pm 0.1$ & $\begin{array}{c}4.9 \pm \\
0.1 \\
\end{array}$ & $4.6 \pm 0.1$ \\
\hline & $40^{\circ} \mathrm{C}$ & & $\begin{array}{c}4.8 \pm \\
0.1 \\
\end{array}$ & $\begin{array}{c}4.6 \pm \\
0.1 \\
\end{array}$ & $\begin{array}{c}4.6 \pm \\
0.1 \\
\end{array}$ & $4.6 \pm 0.1$ & $4.5 \pm 0.1$ & $\begin{array}{c}4.5 \pm \\
0.1 \\
\end{array}$ & $4.4 \pm 0.1$ \\
\hline \multirow{2}{*}{3} & $25^{\circ} \mathrm{C}$ & \multirow{2}{*}{$\begin{array}{c}5.1 \pm \\
0.1\end{array}$} & $\begin{array}{c}5.0 \pm \\
0.1\end{array}$ & $\begin{array}{c}4.8 \pm \\
0.1\end{array}$ & $\begin{array}{c}4.8 \pm \\
0.1\end{array}$ & $4.8 \pm 0.1$ & $4.7 \pm 0.1$ & $\begin{array}{c}4.6 \pm \\
0.1\end{array}$ & $4.5 \pm 0.1$ \\
\hline & $40^{\circ} \mathrm{C}$ & & $\begin{array}{c}5.1 \pm \\
0.1\end{array}$ & $\begin{array}{c}4.8 \pm \\
0.1\end{array}$ & $\begin{array}{c}4.8 \pm \\
0.1\end{array}$ & $4.7 \pm 0.1$ & $4.7 \pm 0.1$ & $\begin{array}{c}4.6 \pm \\
0.1\end{array}$ & $4.5 \pm 0.1$ \\
\hline
\end{tabular}




\begin{tabular}{|c|c|c|c|c|c|c|c|c|c|}
\hline \multirow{2}{*}{4} & $25^{\circ} \mathrm{C}$ & \multirow{2}{*}{$\begin{array}{c}7.2 \pm \\
0.2\end{array}$} & $\begin{array}{c}7.1 \pm \\
0.2 \\
\end{array}$ & $\begin{array}{c}6.7 \pm \\
0.2 \\
\end{array}$ & $\begin{array}{c}6.6 \pm \\
0.2 \\
\end{array}$ & $6.4 \pm 0.2$ & $6.1 \pm 0.2$ & $\begin{array}{c}5.9 \pm \\
0.2 \\
\end{array}$ & $5.9 \pm 0.2$ \\
\hline & $40^{\circ} \mathrm{C}$ & & $\begin{array}{c}7.1 \pm \\
0.2 \\
\end{array}$ & $\begin{array}{c}7.0 \pm \\
0.2\end{array}$ & $\begin{array}{c}6.8 \pm \\
0.2\end{array}$ & $6.5 \pm 0.2$ & $6.4 \pm 0.2$ & $\begin{array}{c}6.3 \pm \\
0.2\end{array}$ & $6.2 \pm 0.2$ \\
\hline \multirow{2}{*}{5} & $25^{\circ} \mathrm{C}$ & \multirow{2}{*}{$\begin{array}{c}7.2 \pm \\
0.2\end{array}$} & $\begin{array}{c}7.1 \pm \\
0.2 \\
\end{array}$ & $\begin{array}{c}6.9 \pm \\
0.2 \\
\end{array}$ & $\begin{array}{c}6.8 \pm \\
0.2 \\
\end{array}$ & $6.4 \pm 0.2$ & $6.3 \pm 0.2$ & $\begin{array}{c}6.3 \pm \\
0.2 \\
\end{array}$ & $6.2 \pm 0.2$ \\
\hline & $40^{\circ} \mathrm{C}$ & & $\begin{array}{c}6.9 \pm \\
0.2 \\
\end{array}$ & $\begin{array}{c}6.7 \pm \\
0.2 \\
\end{array}$ & $\begin{array}{c}6.6 \pm \\
0.2 \\
\end{array}$ & $6.4 \pm 0.2$ & $6.3 \pm 0.2$ & $\begin{array}{c}6.3 \pm \\
0.2 \\
\end{array}$ & $6.2 \pm 0.2$ \\
\hline \multirow{2}{*}{6} & $25^{\circ} \mathrm{C}$ & \multirow{2}{*}{$\begin{array}{c}7.3 \pm \\
0.2\end{array}$} & $\begin{array}{c}7.2 \pm \\
0.2 \\
\end{array}$ & $\begin{array}{c}6.7 \pm \\
0.2 \\
\end{array}$ & $\begin{array}{c}6.6 \pm \\
0.2 \\
\end{array}$ & $6.5 \pm 0.2$ & $6.2 \pm 0.2$ & $\begin{array}{c}6.2 \pm \\
0.2 \\
\end{array}$ & $6.2 \pm 0.2$ \\
\hline & $40^{\circ} \mathrm{C}$ & & $\begin{array}{c}7.1 \pm \\
0.2 \\
\end{array}$ & $\begin{array}{c}6.6 \pm \\
0.2\end{array}$ & $\begin{array}{c}6.5 \pm \\
0.2\end{array}$ & $6.4 \pm 0.2$ & $6.2 \pm 0.2$ & $\begin{array}{c}6.1 \pm \\
0.2\end{array}$ & $6.1 \pm 0.2$ \\
\hline \multirow{2}{*}{7} & $25^{\circ} \mathrm{C}$ & \multirow{2}{*}{$\begin{array}{c}7.2 \pm \\
0.2\end{array}$} & $\begin{array}{c}7.1 \pm \\
0.2 \\
\end{array}$ & $\begin{array}{c}6.6 \pm \\
0.2 \\
\end{array}$ & $\begin{array}{c}6.5 \pm \\
0.2 \\
\end{array}$ & $6.4 \pm 0.2$ & $6.3 \pm 0.2$ & $\begin{array}{c}6.3 \pm \\
0.2 \\
\end{array}$ & $6.1 \pm 0.2$ \\
\hline & $40^{\circ} \mathrm{C}$ & & $\begin{array}{c}7.0 \pm \\
0.2\end{array}$ & $\begin{array}{c}6.3 \pm \\
0.2 \\
\end{array}$ & $\begin{array}{c}6.3 \pm \\
0.2 \\
\end{array}$ & $6.2 \pm 0.2$ & $6.0 \pm 0.2$ & $\begin{array}{c}6.0 \pm \\
0.2 \\
\end{array}$ & $6.0 \pm 0.2$ \\
\hline
\end{tabular}

Tab. 3

\begin{tabular}{|c|c|c|c|c|}
\hline \multirow{2}{*}{ EMULSION } & \multicolumn{2}{|c|}{ BEFORE } & \multicolumn{2}{c|}{ AFTER } \\
\cline { 2 - 5 } & diameter & P.I. & diameter & P.I. \\
\hline $\mathbf{1}$ & $72.4 \pm 1.8$ & 0.207 & $61.9 \pm 0.3$ & 0.094 \\
\hline $\mathbf{2}$ & $81.2 \pm 0.7$ & 0.131 & $80.2 \pm 1.2$ & 0.088 \\
\hline $\mathbf{3}$ & $72.2 \pm 0.2$ & 0.124 & $70.4 \pm 0.1$ & 0.092 \\
\hline $\mathbf{4}$ & $76.2 \pm 0.9$ & 0.133 & $71.2 \pm 1.4$ & 0.040 \\
\hline $\mathbf{5}$ & $73.5 \pm 0.5$ & 0.156 & $66.5 \pm 0.2$ & 0.087 \\
\hline $\mathbf{6}$ & $75.6 \pm 0.1$ & 0.132 & $70.1 \pm 0.3$ & 0.081 \\
\hline $\mathbf{7}$ & $82.9 \pm 0.1$ & 0.193 & $69.5 \pm 0.1$ & 0.090 \\
\hline
\end{tabular}


Tab. 4 


\begin{tabular}{|l|c|c|}
\hline \multirow{2}{*}{ SOLUTION } & \multicolumn{2}{|c|}{ P $_{\text {app }}$} \\
\cline { 2 - 3 } & OCTANOL/WATER & IPM/WATER \\
\hline TM pH 7.2 & $0.20 \pm 0.05$ & $0.10 \pm 0.01$ \\
\hline TM/AOT pH 7.2 & $7.80 \pm 0.25$ & $2.40 \pm 0.10$ \\
\hline TM pH 5.0 & $0.10 \pm 0.01$ & $0.10 \pm 0.01$ \\
\hline TM/AOT pH 5.0 & $8.90 \pm 0.40$ & $2.20 \pm 0.09$ \\
\hline
\end{tabular}

Tab. 5 
Tab. 1: w/w percent composition of nanoemulsions. Each nanoemulsion has the following fixed composition, corresponding to EM 1: 5\% IPM, 1\% LP80, 1.5\% TW80, 0.1\% EDTA, 0.02\% BK, $2.5 \%$ glycerol, water q.b. $100 \%$ (EM 1)

Tab. 2: Emulsions physico-chemical characteristics $( \pm \mathrm{SE})$

Tab 3: emulsions $\mathrm{pH}$ over time at different storage temperature $( \pm \mathrm{SE})$

Tab. 4: : Diameter before and after sterilization $( \pm \mathrm{SE})$.

Tab. 5: Apparent partition coefficient in octanol and IPM of TM and TM/AOT at pH 5.0 e 7.2 $( \pm \mathrm{SE})$ 


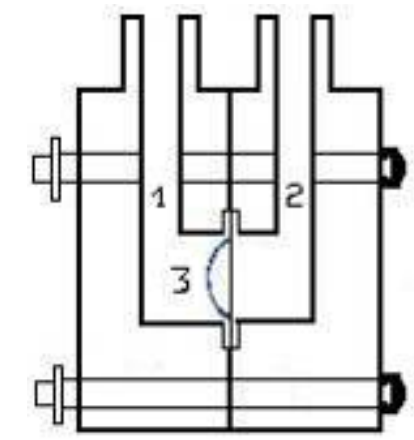

Fig. 1A

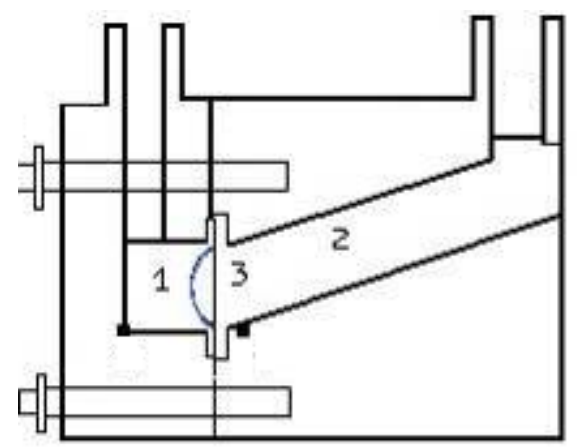

Fig. 1B 


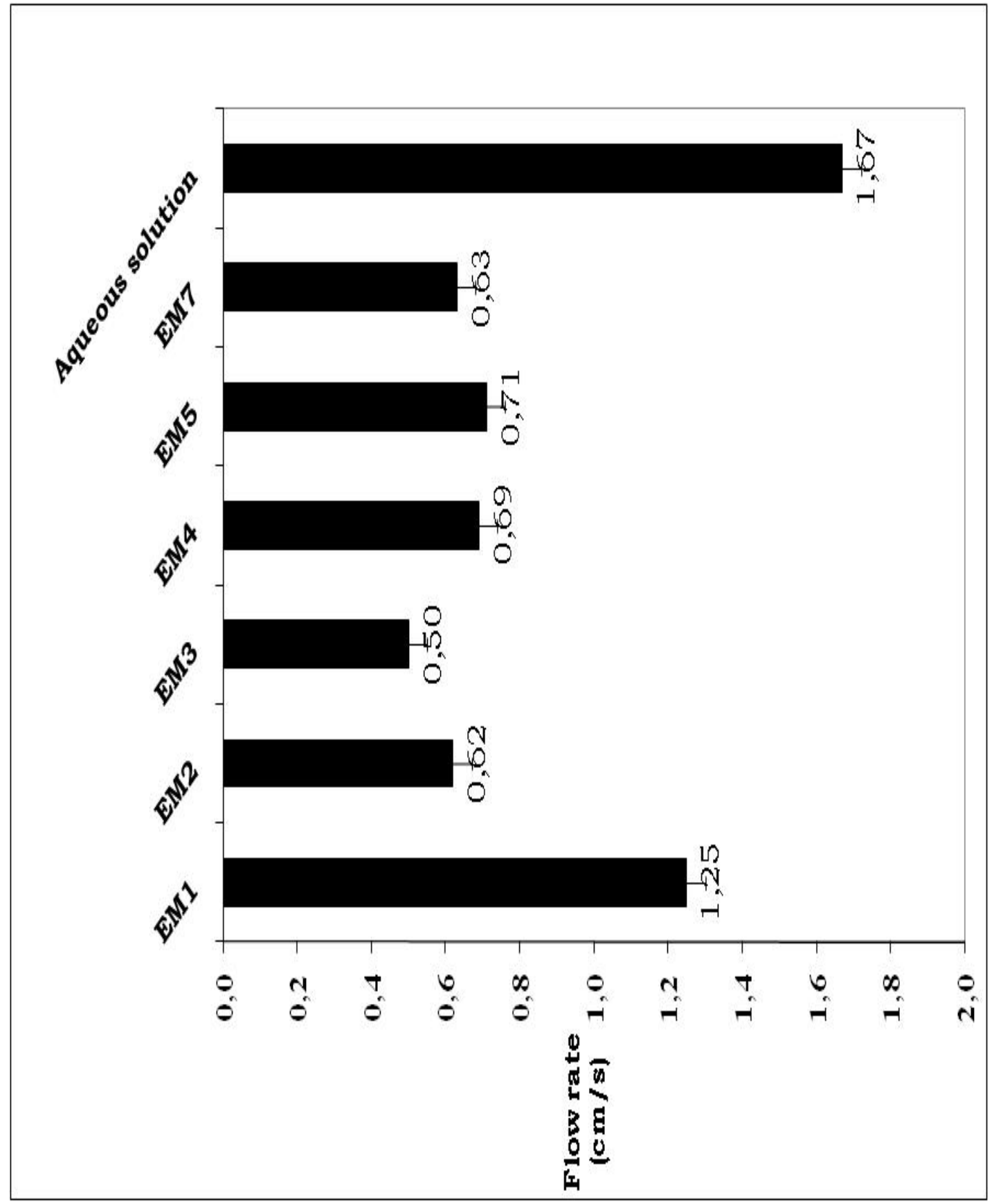

Fig. 2 


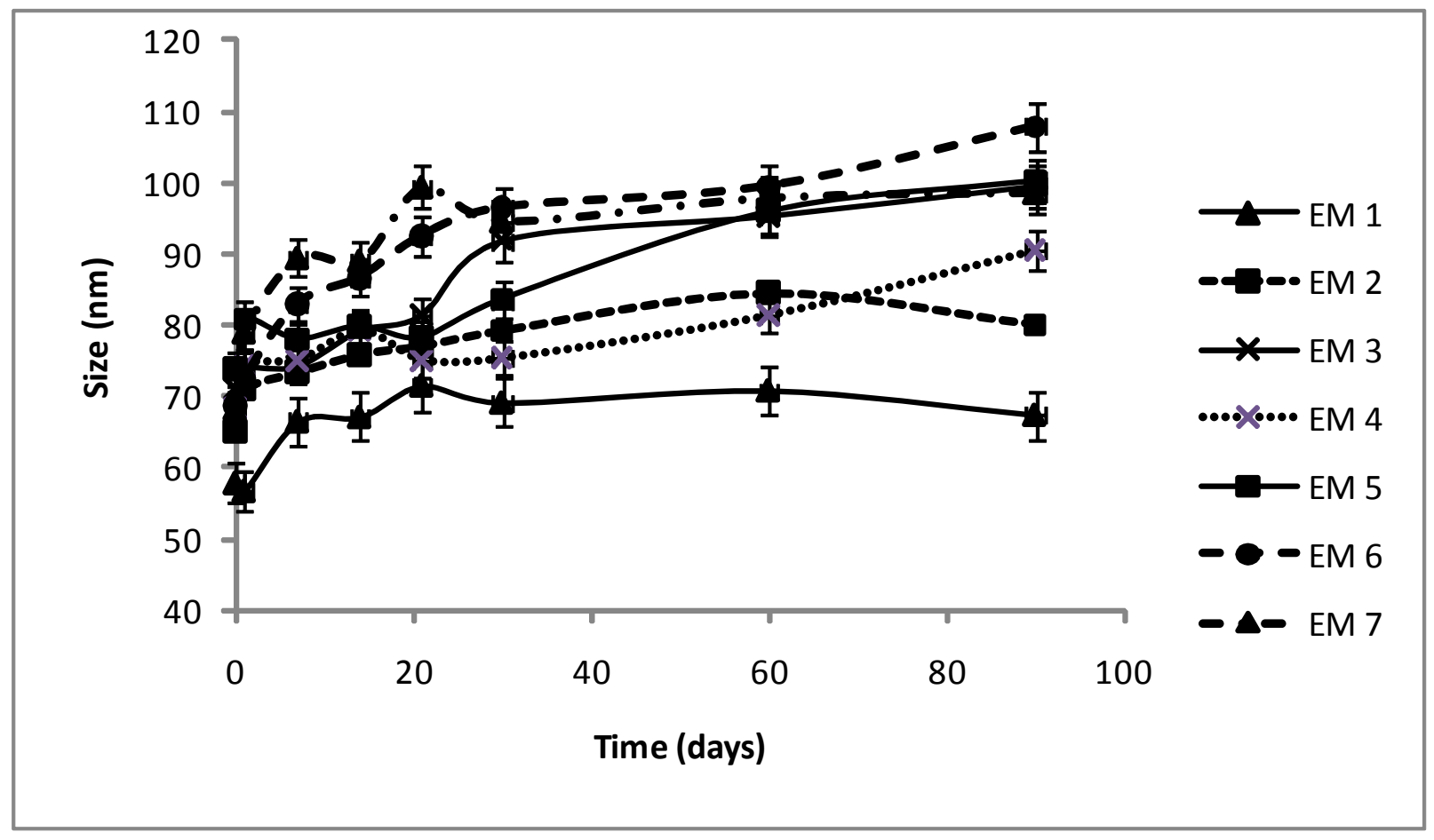

Fig. 3A 


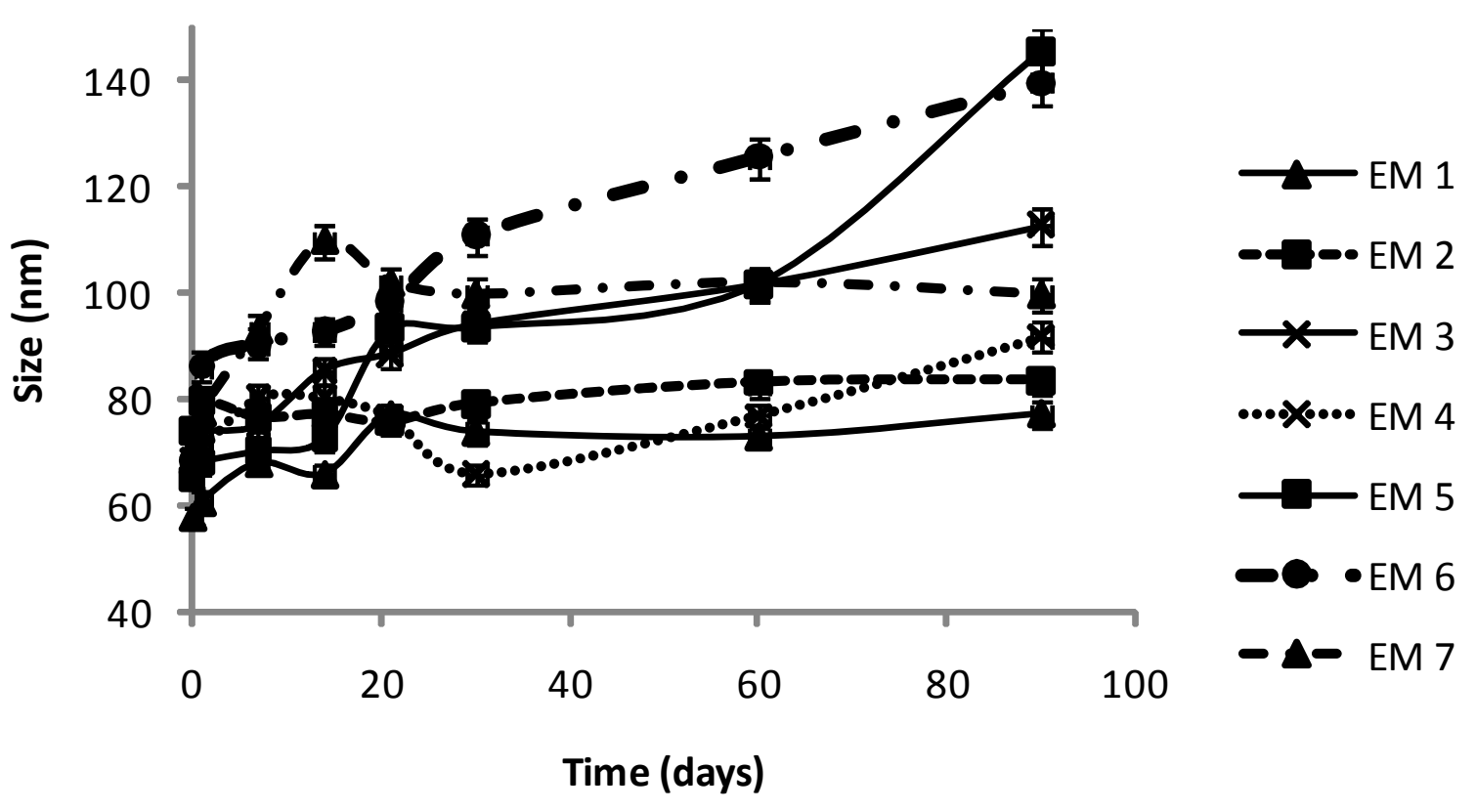

Fig. 3B 


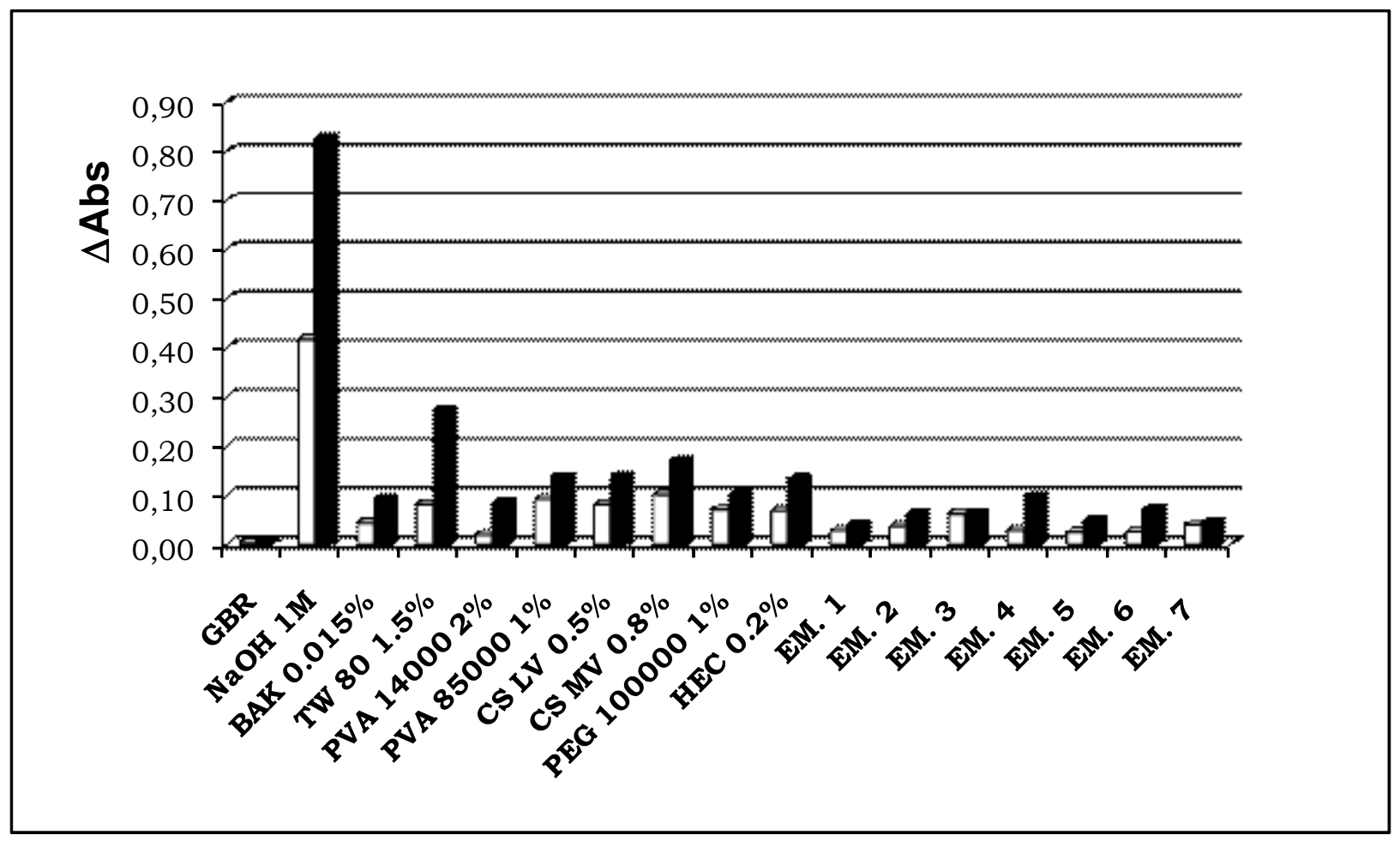

Fig. 4 


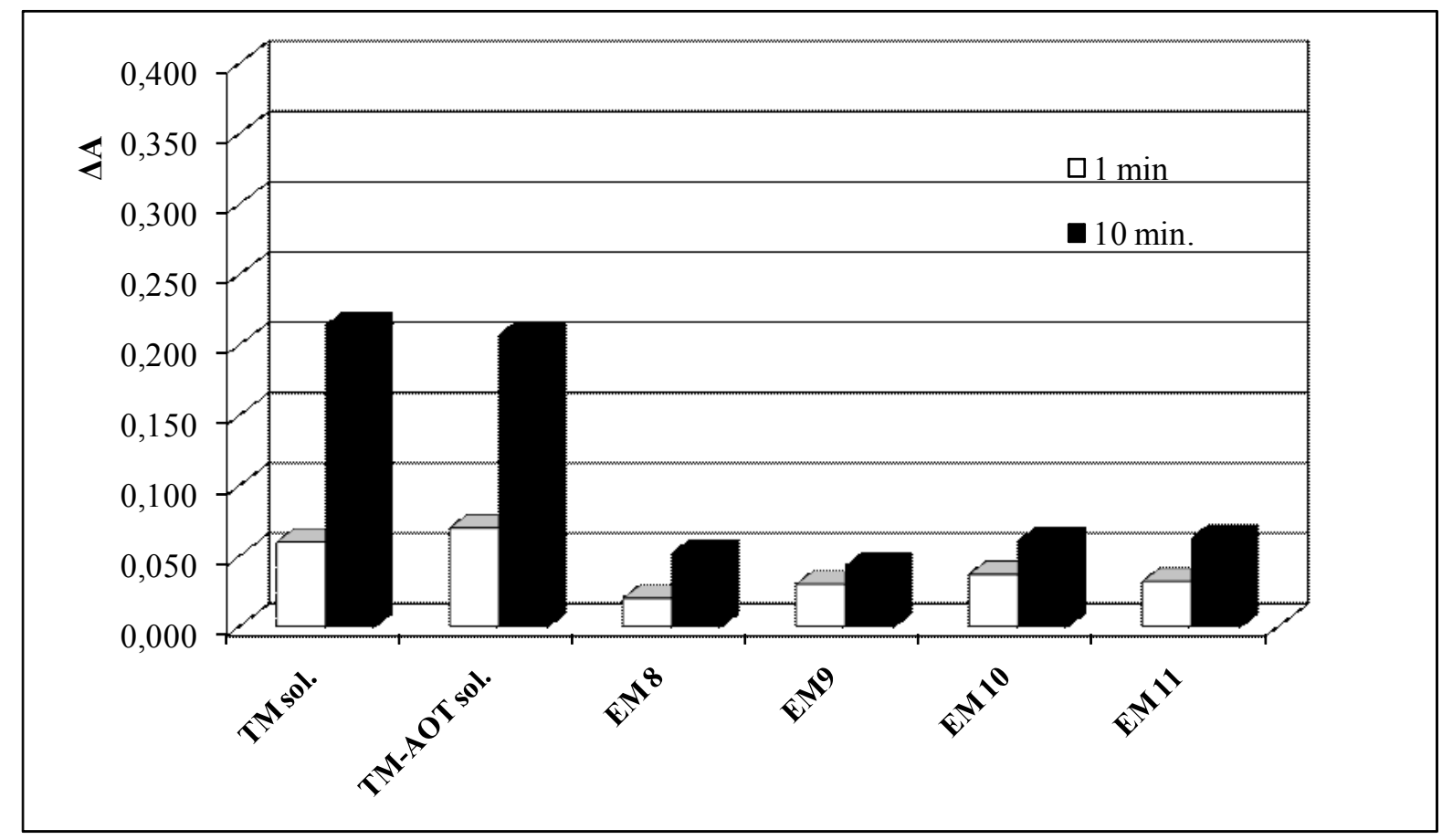

Fig. 5 


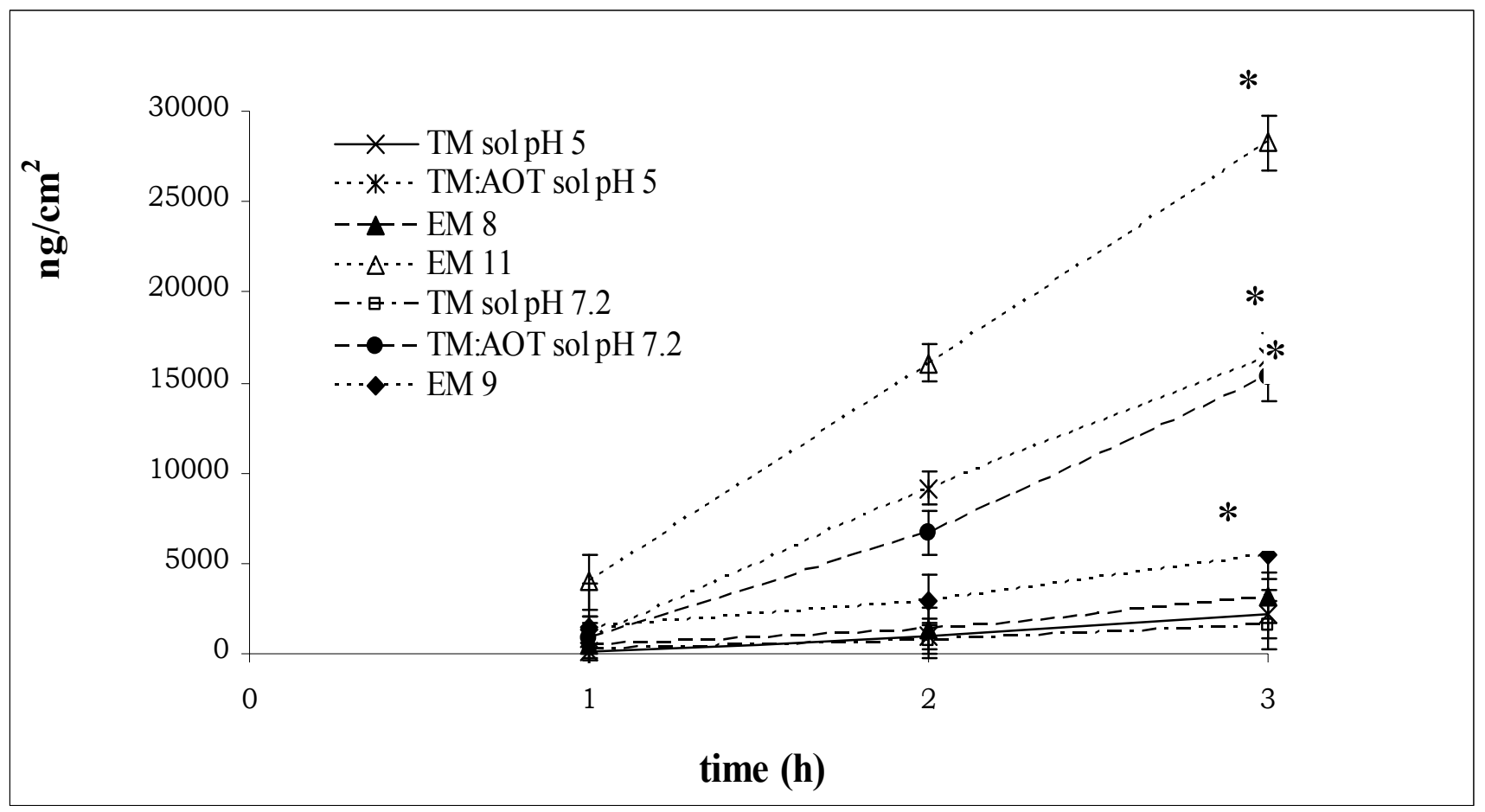

Fig. 6 


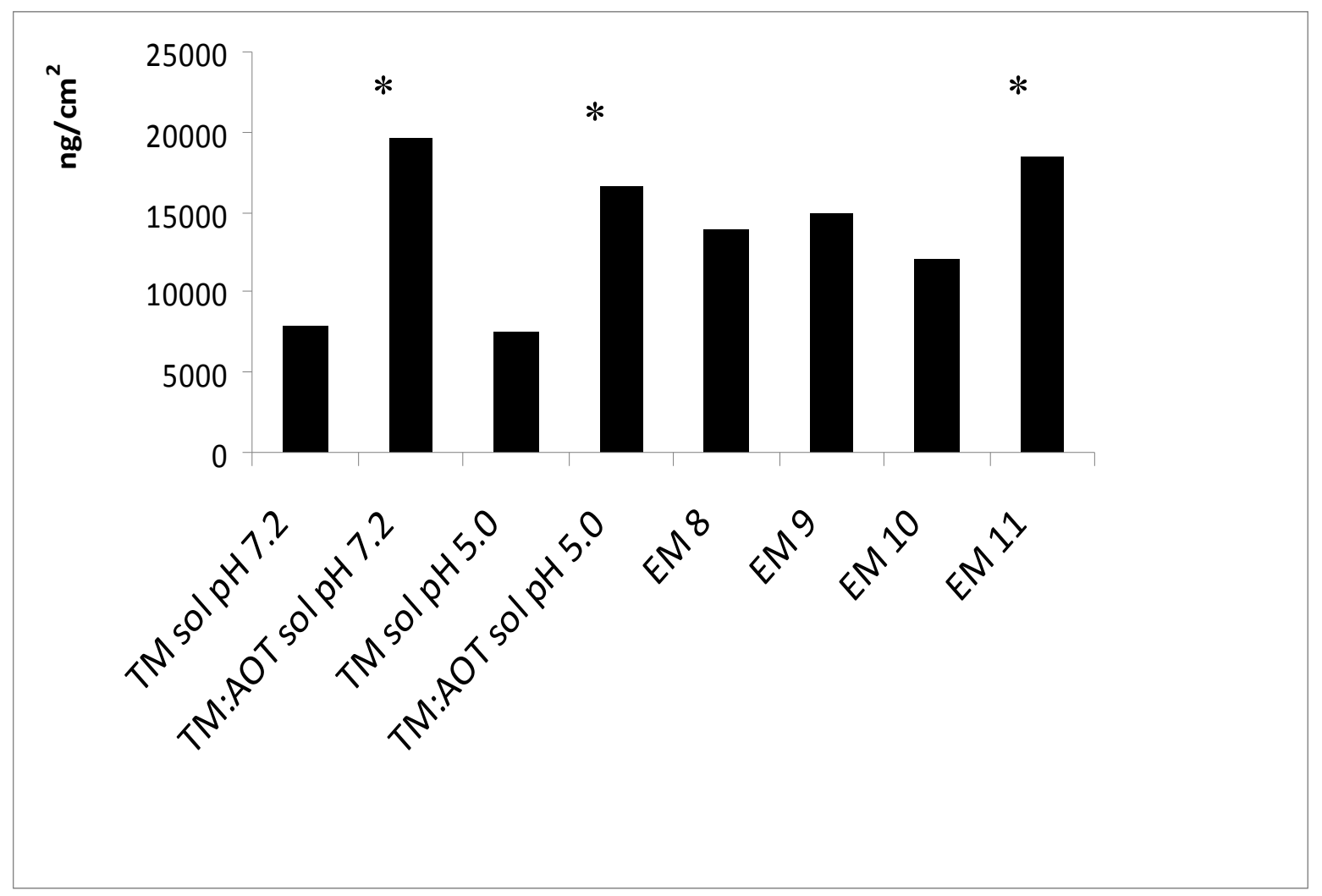

Fig. 7 
Fig. 1A: Corneal opacity holders. 1: donor compartment. 2: receiving compartment. 3: cornea

Fig. 1B: Corneal diffusion chamber. 1: donor compartment. 2: receiving compartment. 3: cornea

Fig. 2: Emulsions flow rates.

Fig. 3A: emulsion droplets mean diameter over time at $25^{\circ} \mathrm{C}$ storage temperature.

Fig. 3B: emulsion droplets mean diameter over time at $40{ }^{\circ} \mathrm{C}$ storage temperature.

Fig. 4: corneal opacity determined as absorbance variation $(\Delta \mathrm{A})$ at $570 \mathrm{~nm}$ after 1 minute $(\mathrm{O})$ and 10 minutes $(\bullet)$ exposure

Fig. 5: TM and TM-AOT containing system corneal opacity determined as absorbance variation $(\Delta \mathrm{A})$ at $570 \mathrm{~nm}$ after 1 minute $(\circ)$ and 10 minutes $(\bullet)$ exposure

Fig. 6: Timolol corneal permeation through the cornea $(* \rightarrow \mathrm{p}<0.05$ referred to $\mathrm{TM}$ aqueous solution at the corresponding $\mathrm{pH}$ value)

\section{Acknowledgements}

Autors from Dipartimento di Scienza e Tecnologia del Farmaco thank Consortium TEFARCO Innova for the research support. 


\section{References}

Aggarwal, D., Kaur, I.P., 2005. Improved pharmacodynamics of timolol maleate from mucoadhesive niosomal ophthalmic drug delivery system. Int. J. Pharm. 290, 155-159.

Ahuja ,H., Dhake, A.S., Majumdar, D.K., 2006. Effect of formulation factors on in vitro permeation of diclofenac from experimental and marketed aqueous eye drops through excised goat corneas. Yakugaku Zasshi 126, 1369-1375.

Badmapriya, D., Rajalakshmi, A.N., 1010. Formulation and evaluation of atropine microemulsion as ocular drug delivery. IJPT 2, 924-931.

Banca delle cornee della regione Piemonte, Co 18.7/2006. Istruzione tecnica per il prelievo delle cornee. www.rianimazione.info/.../PRELIEVI.../CORNEE/...

Camber, O., 1985. An in vitro model for determination of drug permeability through the cornea. Acta Pharm. Suec. 22, 335-342.

Casterton, P.L., Potts, L.F., Klein, B.D., 1996. A novel approach to assessing eye irritation potential using the Bovine Corneal Opacity and Permeability Assay. J. Toxicol. Cutan. Ocul. Toxicol. 15, $147-163$. 
Ciba-Geigy, 1977. Wissenschaftliche Tabellen Geigy, 8th ed. Basel, Ciba-Geigy.

De la Fuente, M., Raviña, M., Paolicelli, P., Sanchez, A., Seijo, B., Alonso, M.J., 2010. Chitosanbased nanostructures: a delivery platform for ocular therapeutics. Adv. Drug Deliv. Rev., 62, 100117.

Fang, J.Y., Hong, C.T., Chiu, W.T., Wang, Y.Y., 2001. Effect of liposomes and niosomes on skin permeation of enoxacin. Int. J. Pharm. 219, 61-72.

Felt, O., Furrer, P., Mayer, J.M., Plazonnet, B., Buri, P., Gurny, R., 1999. Topical use of chitosan in ophthalmology: tolerance assessment and evaluation of precorneal retention. Int. J. Pharm. 180 $185-193$.

Furrer, P., Mayer, J.M., Gurny, R., 2002. Ocular tolerance of preservatives and alternatives. Eur. J. Pharm. Biopharm., 53, 263-280.

Gallarate, M., Gasco, M.R., Trotta, M., 1988. Influence of octanoic acid on membrane permeability of timolol from solutions and from microemulsions. Acta Pharm. Technol. 34, 102-105. 
Gautheron, P.D., Dukic, M., Alix, D., Sina, J.F., 1992. Bovine cornea opacity and permeability test: an in vitro assay of ocular irritancy. Fund. Appl. Toxicol. 18, 442-449.

Gordon, A.M, Kök, M.S., Harding S.E., Adams, G.G., 2010. Polysaccharide drug delivery systems based on pectin and chitosan. Biotechnol. Ge. Engin. Rev. 27, 257-284

Gupta, S., Vyas, S.P., 2010. Carbopol/chitosan based pH triggered in situ gelling system for ocular delivery of timolol maleate. Sci. Pharm. 78, 959-76.

Han, S., Shen, J.,Gan, Y., Geng, H., Zhang, X., Zhu, X., Gan, L. 2010. , Novel vehicle based on cubosomes for ophthalmic delivery of flurbiprofen with low irritancy and high bioavailability Acta Pharmacol. Sin.31, 990-998.

Hasse, A., Keipert, S., 1997. Development and characterization of microemulsions for ocular application. Eur. J. Pharm. Biopharm. 43, 179-183.

Herman, C.J., Groves, M.J., 1992. The influence of free Fatty Acid Formation on the pH of Phospholipid-stabilized Emulsions. Pharm. Res. 10, 5, 774-776. 
Higashiyama, M., Inada, K., Ohtori, A., Tojo, K., 2004. Improvement of the ocular bioavailability of timolol by sorbic acid. Int. J. Pharm. 272, 91-98.

Hung-Hong, L., Shiu-Man, K., Li-Ren, H., Yi-Hung, T., 1996. The preparation of norfloxacinloaded liposomes and their in-vitro evaluation in pig's eye. J. Pharm. Pharmacol. 48, 801-805.

Hussein, O., Ammar, H., Salama, A., Ghorab, M., Mahmoud, A.A., 2009. Nanoemulsion as a Potential Ophthalmic Delivery System for Dorzolamide Hydrochloride. AAPS Pharm. Sci. Tech. $10,808-819$.

Indu, P.K., Meenakshi K., 2002. Ocular preparations: the formulation approach. Drug Develop. Ind. Pharm. 28, 473-493.

Kabalnov, A., Tarara, T., Arlauskas, R., Weers, J., 1996. Phospholipids as emulsion stabilisers: 2. Phase behaviour versus emulsion stability. . Colloid Interface Sci. 184, 227-235.

Lee, V.H.L., 1993. Precorneal, corneal and postcorneal factors, in: Mitra, A.K. (Eds.), Ophtalmic Drug Delivery Systems, Drug and the Pharmaceutical Science. Marcel Dekker Inc., New York, Basel, and Hong Kong, pp 59-81. 
Ligório Fialho, S., da Silva-Cunha, A., 2004. New vehicle based on a microemulsion for topical ocular administration of dexamethasone. Clin. Exp. Ophthalmol. 32, 626-632.

Ludwig, A., 2005. The use of mucoadhesive polymers in ocular drug delivery. Adv. Drug Deliv.

Rev. 57, 1595-1639.

Ogawa, S., Decker, E.A., McClements, D.J., 2002. Production and characterization of o/w emulsions containing cationic droplets stabilized by lecithin-chitosan membranes. J. Agric. Food Chem. 51, 2606-2812.

Saettone, M.F., Salminen, L., 1995. Ocular insert for topical delivery. Adv. Drug Deliv. Rev. 16, 95-106.

Steinhardt, R.A., 2003. Cornea preservation medium. US Patent 7087369.

Suh, H., Jun, HW., 1996. Effectiveness and mode of action of isopropyl myristate as a permeation enhancer for through shed snake skin. J. Pharm. Pharmacol. 48, 812-816.

Tamilvanan, S., Benita, S., 2004. The potential of lipid emulsion for ocular delivery of lipophilic drugs. Eur. J. Pharm. Biopharm. 58, 357-368. 
Thermes, F., Rozier, A., Plazonnet, B., Grove, J., 1992. Bioadhesion: The effect of polyacrylic acid on the ocular bioavailability of timolol. Int. J. Pharm. 81, 59-65.

Tiffany, J.M., 2006. Surface tension in tears. Arch. Soc, Esp. Oftalmol. 81, 363-366

Ubels, J.L., Ditlev, J.A., Clousing, D.P., Casterton, P.L., 2004. Corneal permeability in a redesigned corneal holder for the bovine cornea opacity and permeability assay. Toxicol. Vitro, 18, 853-857.

Van Ooteghem, M.M., 1993. Formulations of ophthalmic solutions and suspensions. Problems and advantages, in: Edman P. (Eds.), Biopharmaceutics of ocular drug delivery, Boca Raton, pp 31-32.

Vandamme, T.F., 2002. Microemulsions aìs drug delivery systems: recent developments and future challenges. Prog. Retin Eye Res. 21, 15-34.

Wadhwa, S., Paliwal, R., Paliwal, S.R., Vyas, S.P., 2010. Hyaluronic acid modified chitosan nanoparticles for effective management of glaucoma: development, characterization and evaluation. J. Drug Target. 18, 292-302.

Wei, J., He H.L., Zheng C.L., Zhu, J.B., 2011. Chitosan-coated ophthalmic submicron emulsion for pilocarpine nitrate. Yao Sue Sue Bao, 46, 990-996. 
Wilhelmus, K.R., 2001. The draize eye test. Surv. Ophtalmol. 45, 493-515. 